In a careful examination, however, of the whole arguneit of the authors of the "Unseen Universe," it looks to me as though they saw clearly to what their course of reasoning, as far as this particular point is concemed, tended, but were willing to stop short of the true logical result, believing that humanity was not yet prepared to admit that we are only a small part of one stupendous whole, a universe of individual life.

Of the main object and scope of their argument I have nothing to say, only this: if the premises assumed-and they are the assumptions of the modern school of science-are correct, there is nothing unreasonable in the conclusions at which the authors have arrived.

NoTe.-Since writing the above I have seen the authors' preface to the second ed:tion of the "Unseen Universe," in which they say: "To reduce matiers to order, we may confidently assert that the only reasonable and defensive alternative to our hypothesis (or, at least, something similar to it) is the stupendous 'pair of assumptions that visible matter is eternal, and that IT IS ALIVE. If anyone can be found to uphold noti ns like these (from a scientific point of view), we shall be happy to enter tine lists with him." If the distinguished authors will confine themselves to this proposition, that "All visiole aggregations of matter, such as our earth and its congeners, are living orgauisations, in other words, ARE ALIVE," I think the affirmative can be successfully maintained.

Whether matter is eternal and each individual particle or atom of matter is alive, is too far in the interior of the unknowable to be discussed with any possibility of successful results, and, too, the idea of an atom heing a living organisation is directly opposed to the whole theory of atomicity, and scientifically ludicrous in view of that theory.

City of Williamsport, Pa., U.S., Narch ro

\section{Prof. Tait on the Earth's Age}

TT is well known that Sir W. Thomson has concluded, from different lines of argument, that the age of the earth, as a body coul enough for habitation, cannot be mich greater than a hundred million years.

Prof. Tait, in his "Recent Advances in Plyysical Science," recapitulates these arguments, hit with a different conclusion. He states the limit of age to be about teit million years.

As the subject is of imaiense interest, may $I$ ask Prof. Tait to explain this changre of conclusion? J. J). EVERETT

\section{A Relapseä Donkey}

Some years ago on one of the Lucknow roads I met a "Yhobi" (washermas) with some donlieys. I send you a picture of one of them, made by a rative artist. It shows, I think, the relintionship between the zebra and the doniley better than many which I have scen. Mules and horses often show zebra marks on their legs, but I have never befre or since seen the marks so well displayed on the trunk and legs as in this donkey. The stripes on the body are blended together at their base, and so are the stripes on the legs blended into bands. At the time I endeavoured to find out whether in the days of the kings of Ondh there had been any zebra in Lucknow which might have bred with donkeys, but could find notining about it. Had there been a zeira winith bred with co.iseys, I think theic would have been more of these striped animals; but this is the only one I have seen since 1858 . I think it a case of simple atazism. Perliaps you may think it worthy of a record in NatuRE. All "Dholis" donkcys are sinall, wretched creatures, mostly with crooked legs.

E. BoNAVIA

Lucknow, fieb. 29

\section{OUR ASTRONOMICAL COLUMN}

VARIARLE STARS.-Mr. J. E. Gore, M.R.I.A., of Umballa, Punjab, calls attention to a star of the sixth magnitude $\epsilon$ nter ed in Harding's Atlas, between $\epsilon$ Leporis and B.A.C. I 553, and which is underlined. Mr. Gore says : "In February of this year, with a 3 -inch refractor, I found Harding's $6 \mathrm{~m}$. star a little brighter than the $9 \mathrm{~m}$. star south of it, but less than several $8 \mathrm{~m}$. stars (Harding) following. It has a small companion $f$ at about $\mathbf{I}^{\prime} \pm$. Harding's $9 \mathrm{~m}$. stars seem about ro m." Reading off from the Atlas the position of the sixth magnitude for 1800 appears to have been about R. s. $^{\circ} 73^{\circ} 32^{\prime \prime} 5$, N.P.D. I I I $25^{\prime}$, whence for $1876^{\circ}$ o we have R.A. $4 \mathrm{~h}$. $57 \mathrm{~m}$. $25 \mathrm{~s}$, N.P.D. I $\mathrm{I}^{\circ} \mathrm{I} \mathrm{S}^{\prime}$. This star does not occur in Argelander's Zones, nor in the Washington Zones in the volumes of observations for 1870 and $\mathrm{I} 87 \mathrm{I}$.

Gilliss has this note to No. 543 of his Catalogue of I 248 stars for 1840 (B.A.C. 38 I 5 ): " Probably variable at very short intervals. Of the seven observations three estimations make it 6th magnitude, three 5 th, and the other $5.6 . "$ This star, which was observed by Flamsteed, Bradiey, Piazzi, and Taylor, was also observed by Argelander on three nights, viz., I850, March 15, 1851, April 22 and 28 , the magnitudes being noted on these occasions, $5,7,6$ respectively. It appears not unlikely that if this star is examined at short intervals Gilliss's suspicion of variability will be confurmed. It is situate in Hydra R.A. (I876), I rh. 2 m. 45s., N.P.D. $117^{\circ} 25^{\prime}$.

As perhaps connected with the subject of variable stars, we may refer to a remark by Piazzi, applying to his star XVI. 35. He says: "Fortiter micans, intereadem, sequens tranquilla luce splendescit." No. 35 is called $8 \mathrm{~m}$., and the star following $15^{\prime \prime}$. and south $18^{\prime \prime}$, which did not exhibit the strong scintillation of its neighbour, $6 \mathrm{~m}$. Both stars occur in the Washington Zone, I847, June I7, magnitudes 7.8 and $6 \%$. Also to the remark attached by Laiande to the star of 8.9 mag. observed on the middle wire at 2oh. 35m. 39 5s., I 796, August 23, "Beaucoup de scintillation" ("Histoire Céieste," p. 242) ; this star is No. 40102 Cygnus, of the reduced catalogue, R.A. (1876), 2oh. $39 \mathrm{~m}$. 23 s. N.P.D. $58^{\circ} 45^{\prime} \cdot 2$. Several of the variable stars are well known to exbibit striking scintillation at times, and perhaps more especially when on the point of diminution; this has been particularly the case with $S$ Virgini ; (Hind, I 85 I), in whichireddish-yellow star flashes of a deeper red are occasionally present, producing an impression of unusual scintillation.

The star Lalande 34746 Aquila is of a deep orange colour. Its position is erroneously given in the reduced catalogue from the observation 1796 , June 25 ; the N.P.D. should be $96^{\circ} 43^{\prime} 28^{\prime \prime} 7$. It does not occur in the Zones of Bessel or Santini. Lalande calls it $7 \mathrm{rn}$., and it is entered of the same magnitude in the charts of Capocci and Inghirami. In September, 1873 , it was 7.8 , so that at present a claim to be included in the list of variables is not quite made out; still as so large a proportion of the highlycoloured stars do prove to be variable, L. 34746 may be worth watching. Position for I $875^{\circ}$ o. R.A., 1Sh. $38 \mathrm{~m} .2 \mathrm{2s}$., N.P.D., $96^{\circ} 39^{\prime} 5$

Several of the variable stars to which attention has been called in this column during the last twelvemonth, are now in favoulable positions for observation.

The Siarch for Comets.-No new telescopic comet has been detccted since that found by M. Borrelly at Marseilles early in December 1874, an interval of more than sixteen months. Perhaps we may attribu.e this circumstauce partly to the very unfivourable weather which has prevailed generally during the last year, but it is preity certain that if a systenatic search for these bodies, with suitable instruments, could be instituted isy aid of andateurs of the southern hemisphere, cometary astronomy would be greatly the gainer. Such work is not adapted to tine routime of the public observatories, nor can they afford, in the actual state of what may be termed the standard astronomy of the other hemisphere, to devote time to it ; but it is an occupation especially within the province of the amateur. If his instrumcatal means are not equal to the determination of accurate positions, he may conteut himself with intimating any discovery to the astronomers in charge of the public establishments who, after receiving indication of the approximate position of any new comet, will no doubt secure observations sufficient for the calculation of the orbit. In this way it is highly probable that the number of known comets of short period may be materially increased, since it is only at certain returns. 